\title{
Meeting report of the "Symposium on kidney stones and mineral metabolism: calcium kidney stones in 2017"
}

\author{
Agnieszka Pozdzik ${ }^{1,2} \cdot$ Naim Maalouf $^{3} \cdot$ Emmanuel Letavernier $^{4,5} \cdot$ Isabelle Brocheriou $^{6,7}$. Jean-Jacques Body ${ }^{8}$. \\ Benjamin Vervaet ${ }^{9} \cdot$ Carl Van Haute $^{10} \cdot$ Johanna Noels $^{10} \cdot$ Romy Gadisseur $^{11}$. Vincent Castiglione ${ }^{11}$. \\ Frédéric Cotton ${ }^{12}$. Giovanni Gambaro ${ }^{13} \cdot$ Michel Daudon $^{4,5} \cdot$ Khashayar Sakhaee $^{3}$
}

Received: 3 October 2018 / Accepted: 16 January 2019 / Published online: 24 January 2019

(C) Italian Society of Nephrology 2019

\begin{abstract}
A symposium on kidney stones and mineral metabolism held on December 2017 in Brussels, Belgium was the first international multidisciplinary conference of the International Collaborative Network on Kidney Stones and Mineral Metabolism. This meeting addressed epidemiology, underlying pathophysiological mechanisms, genetics, pathological, as well as clinical and research topics. The participants included clinicians and recognized experts in the field from Europe and the United States interacted closely during the symposium which promoted a chance to explore new frontiers in the field of kidney stone disease. This manuscript summarizes some of the major highlights of the meeting.
\end{abstract}

Keywords Kidney stones $\cdot$ Nephrocalcinosis $\cdot$ Nephrolithiasis $\cdot$ Chronic kidney disease $\cdot$ Hypercalcemia $\cdot$ Hypercalciuria . Hyperoxaluria

\begin{tabular}{llll}
\multicolumn{2}{l}{ Abbreviations } & KSF & Kidney stones formers \\
$\mathrm{CaOx}$ & Calcium oxalate & KSD & Kidney stones disease \\
$\mathrm{CKD}$ & Chronic kidney disease & UA & Uric acid \\
$\mathrm{CN}$ & Crystalline nephropathy & XRD & X-ray diffraction
\end{tabular}

ESKD End-stage kidney disease

FTIR Fourier transform infrared spectroscopy

ICNKSMM International Collaborative Network on

Kidney Stones and Mineral Metabolism

Agnieszka Pozdzik

Agnieszka.Pozdzik@chu-brugmann.be

7 INSERM Unit U1155, Paris, France

1 Kidney Stones Clinic, Nephrology and Dialysis Clinic, Centre Hospitalier Universitaire, Brugmann Hospital, Brussels, Belgium

2 Faculty of Medicine, Université Libre de Bruxelles (ULB), Brussels, Belgium

3 Department of Internal Medicine, and Charles and Jane Pak Center for Mineral Metabolism and Clinical Research, University of Texas Southwestern Medical Center, Dallas, TX, USA

4 Service des explorations fonctionnelles multidisciplinaires, Tenon Hospital, AP_HP, Paris, France

5 INSERM UMRS 1155, Université Pierre et Marie Curie-Paris VI-Sorbonne Universités, Paris, France

6 Department of Pathology, Pitié-Salpêtrière Hospital, Sorbonne University, Paris, France

8 Department of Internal Medicine, Brugmann Hospital, Centre Hospitalier Universitaire, Université Libre de Bruxelles (ULB), Brussels, Belgium

9 Laboratory of Pathophysiology, Antwerp University, Antwerp, Belgium

10 Department of Urology, Brugmann Hospital, Centre Hospitalier Universitaire, Université Libre de Bruxelles (ULB), Brussels, Belgium

11 Department of Clinical Chemistry, EuSpLM, Laboratories "Emergency, Allergy, Urolithiasis", University Hospital of Liège, Liège, Belgium

12 Department of Clinical Chemistry, LHUB-ULB, Brussels, Belgium

13 Division of Nephrology and Dialysis, Gemelli University hospital, Rome, Italy 


\section{Introduction}

Kidney stone disease (KSD) is a common disorder of mineral metabolism worldwide [1]. Its prevalence is rising, causing significant morbidity with a considerable economic impact, in particular among older adults compared to younger adults [2-4]. According to the latest estimate from 2007 to 2010 from the National Health and Nutrition Examination Survey (NHANES), the overall prevalence of kidney stones (KS) in the United States was $10.6 \%$ in men and $7.1 \%$ in women [5]. Therefore, 1 in 11 individuals in the United States had a history of kidney stones, in contrast to the previous estimate of 1 in 20 in the United States population from the late 1980s [5]. A similar rise in prevalence was detected in many European countries $[6,7]$.

Conditions associated with metabolic syndrome are risk factors for $\mathrm{KS}$ formation in general, and uric acid stones in particular [5, 8-10]. However, calcium-based stones remain by far the most commonly encountered KS $[8,10$, 11], and hypercalciuria is the most frequently identified metabolic abnormality in calcium stone formers $[9,12]$.

In recent years, KS has emerged as a multi-systemic disorder. In general, kidney stone formers independent of their stone composition have twice the risk of CKD compared to non-stone formers [13-15]. Nephrolithiasis can impair kidney function with complications such as obstruction, infection, or secondary to urological procedures, or may be primary in nature with parenchymal damage induced by the underlying conditions leading to stone formation such as monogenic disorders, nephrocalcinosis, and primary and secondary hyperoxaluria [16].

The International Collaborative Network on Kidney Stones and Mineral Metabolism (ICNKSMM) held in Belgium in December 2017 (http://www.chu-brugmann. be/en/news/20171207-kidneystones.asp) bridged together practitioners and academicians in the field to develop a common program dedicated to understanding the underlying pathophysiologic mechanisms, genetics, as well as diagnosis and management of the population of stone formers. Another major goal of the Symposium was to cultivate interest among young physicians to engage in kidney stone research in the future.

\section{Genetics of nephrocalcinosis and nephrolithiasis}

The etiology of the most frequent forms of calcium stones nephrolithiasis is multifactorial; involving nutritional, environmental, and polygenic genetic determinants according to Prof Giovanni Gambaro from Nephrology and Dialysis Division, Gemelli University Hospital from Italy. Nephrolithiasis is a common condition, and genetics play a central role in defining the metabolic "milieu" from which KS may form [17-19]. There is a clustering of KS in nearly $50 \%$ of KSF families. Family history of KSD is significantly associated with more complex presentation and higher recurrence rate in idiopathic calcium KSF [20].

$\mathrm{KS}$ are frequently associated with urinary metabolic disorders including as hypercalciuria (40 to $75 \%$ ), hyperoxaluria (5 to $20 \%$ ), hyperuricosuria $(\sim 10 \%)$ and hypocitraturia (20\%). Idiopathic hypercalciuria and calcium stone disease is indeed a complex (multifactorial and polygenic) [21] condition resulting from dietary - environmental interactions in a genetically predisposed subject. Heritability and environment effects have been reported in 56\% and $44 \%$ respectively [17]. Genome wide association studies (GWAS) in Iceland and Japan have found 8 genes that modulate the risk but are not necessarily directly responsible for KSD [22, 23]. Mendelian disorders causing renal stones and nephrocalcinosis involve mutations in the genes of the calcium sensing receptor, soluble adenylyl cyclase, vitamin D receptor, claudins, chloride channels, sodium/ phosphate transporter, carriers involved in the pathogenesis of distal renal tubular acidosis, genes involved in renal morphogenesis, and medullary sponge kidney, as well as many others (Table 1, adapted from [24-27]) [28].

Recent genetic studies led by a single group using exon sequencing of selected gene panels and whole exome sequencing suggested that monogenic disorders may be more common than previously suspected in kidney stone disease [29-31]. In fact, 14 monogenic genes caused nearly $15 \%$ of kidney stones in a population of 26 consecutive recurrent KSF [29]. However Prof Gambaro emphasized the high number of pediatric cases and the potential for some selection bias in these studies.

In patients with primary hyperoxaluria in whom no mutation is identified in the coding regions of the three known genes responsible for primary hyperoxaluria (types 1,2 , and 3 ), testing for mutations in non-coding regions (promoter, introns) or in other gene encoding proteins of oxalate metabolism has been suggested in the further explorations of phenotype-genotype relationships [32]. Diagnosing genetic forms of nephrolithiasis is crucial for personalized medicine in stone formers [33]. 


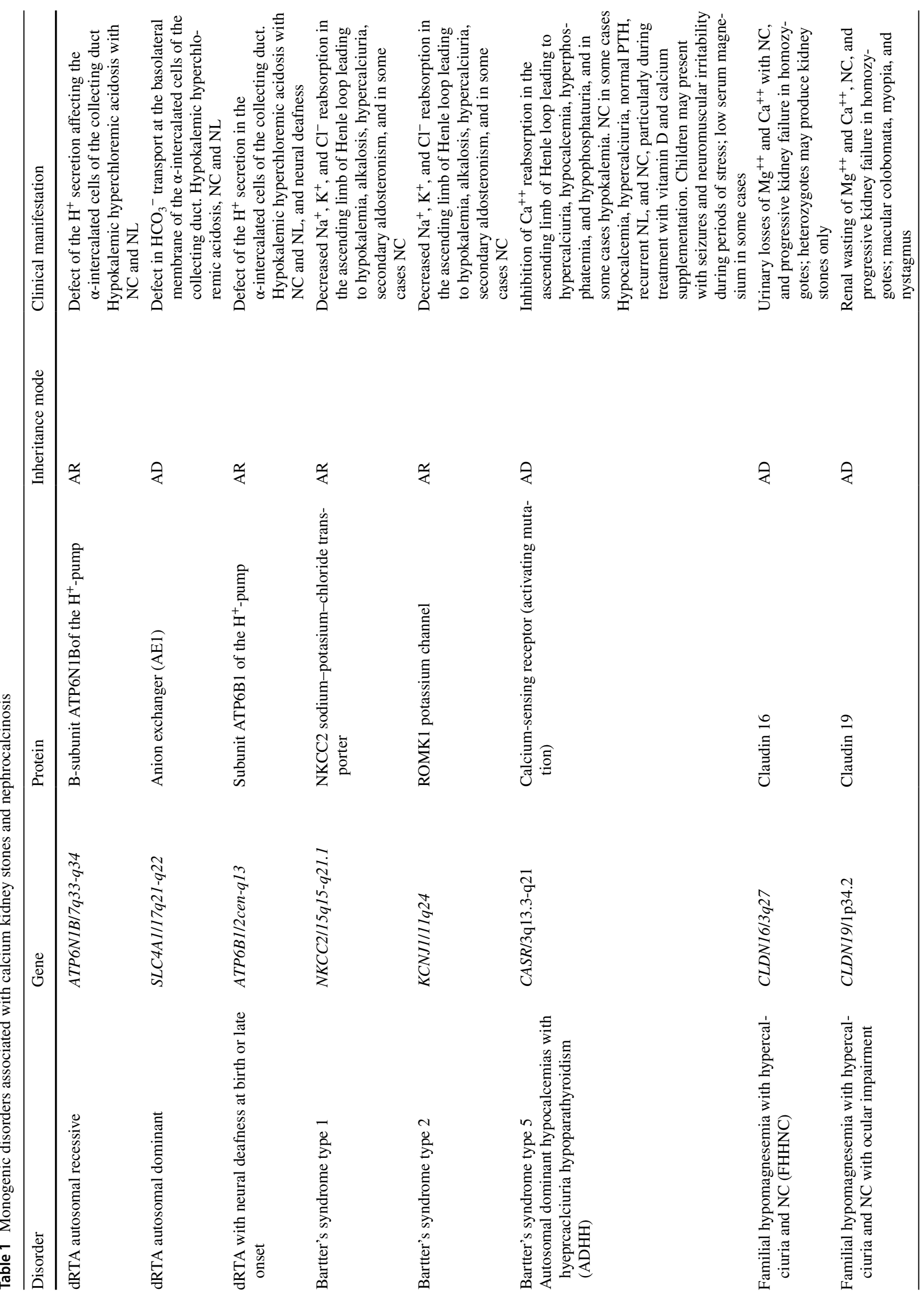




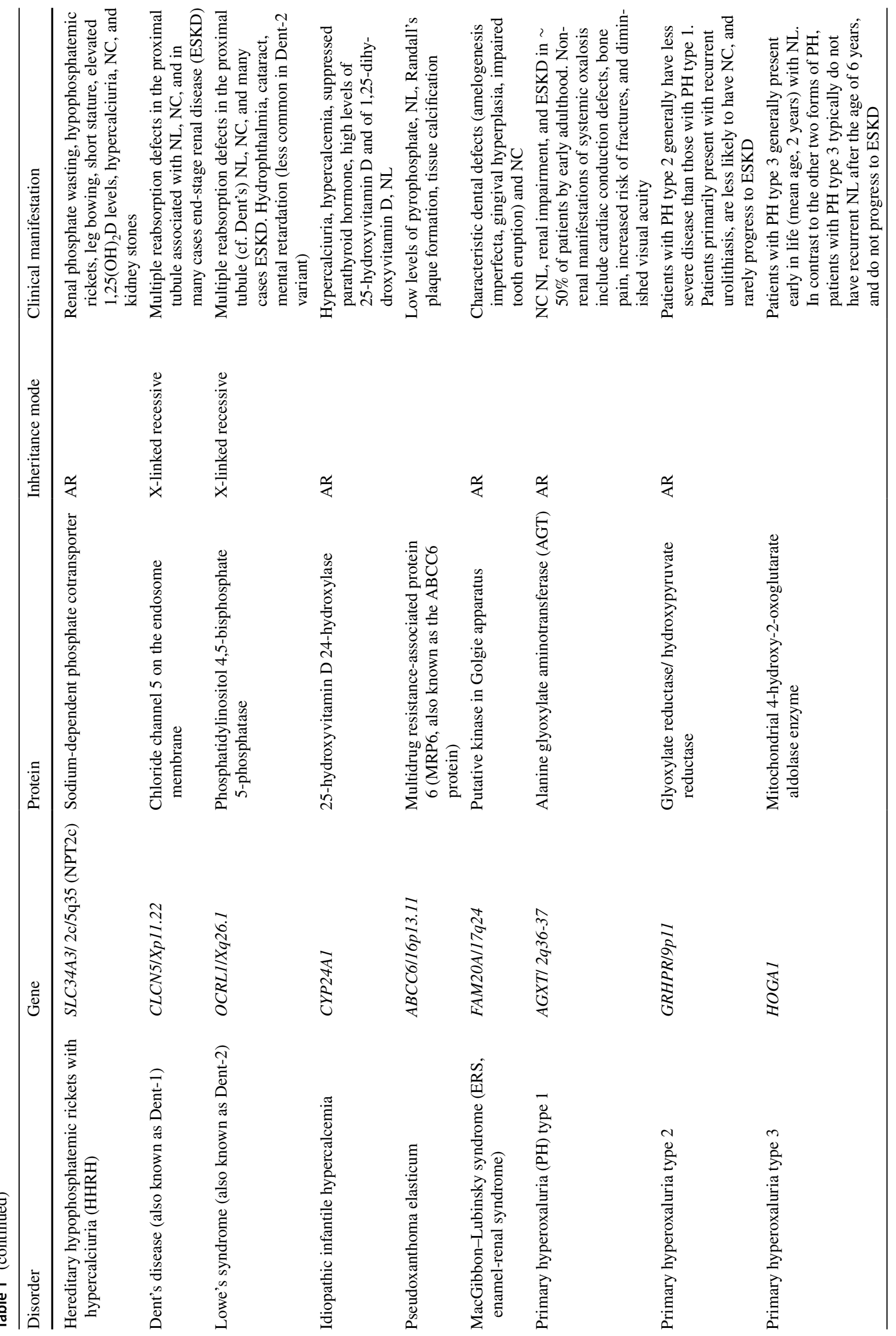




\section{Epidemiology, morphoconstitutional classification and its correlates with pathogenesis and epidemiology of kidney stones}

The incidence of KSD has progressively increased during the past 30 years in most industrialized countries underlined Prof Michel Daudon, head of the Centre de Recherches et d'Informations Scientifiques et Techniques Appliquées aux Lithiases (Laboratoire CRISTAL) since 1986 and responsible for a National Quality Control Program on Stone Analysis in France since 1990.

Urolithiasis affects between 5 and $12 \%$ of the general population and two times more often males than females. However, a trend to a decrease of the male-to-female ratio has been recently reported in some countries. Calcium oxalate $(\mathrm{CaOx})$ stones are the most common urinary calculi, accounting for more than $70 \%$ of all stones in large series published from the beginning of the 1980s. However, differences are found in chemical composition and crystalline phases according to the patient's gender: calcium phosphate is more frequent in female (27.1 vs. 9.7\% in males, $\mathrm{p}<0.0001$ ) while $\mathrm{CaOx}$ is more frequent in male patients $(74.9 \%$ vs $57.9 \%$ in females, $\mathrm{p}<0.0001)$. Stone composition also varies with age in both genders, as a consequence of changes in lithogenic risk factors. For example, uric acid (UA) stones are infrequent in young stone formers and become the prevalent category in oldest patients in relation to the increase of body mass index and of the type 2 diabetes prevalence. By contrast, among $\mathrm{CaOx}$ stones, weddellite is more common in younger than in older patients.

Prof Daudon highlighted that physical methods, mainly $\mathrm{X}$-ray diffraction (XRD) and Fourier transform infrared spectroscopy (FTIR) reliably identify specific forms of nephrolithiasis involving non-calcium components such as cystine, purines or drugs $[34,35]$. For calcium stones, these methods provide information on chemical $(\mathrm{CaOx}$ and/or calcium phosphate) and crystalline phases, which appears more clinically relevant. However, the same crystalline phase may result from a variety of pathological conditions. Stone analysis combining morphological examination followed by XRD or FTIR analysis of the core, middle layers, and surface of calculi provides a more complete understanding of etiologic diagnosis than compositional analysis alone. Using this morphological method, stones may be classified into 7 types subdivided in 22 subtypes (Table 2 adapted from [36]) [37]. While crystalline phases may point out the main metabolic disorders involved in stone formation, morphological type is highly suggestive for specific lithogenic processes. Thus, whewellite, which is mainly related to hyperoxaluria, may 


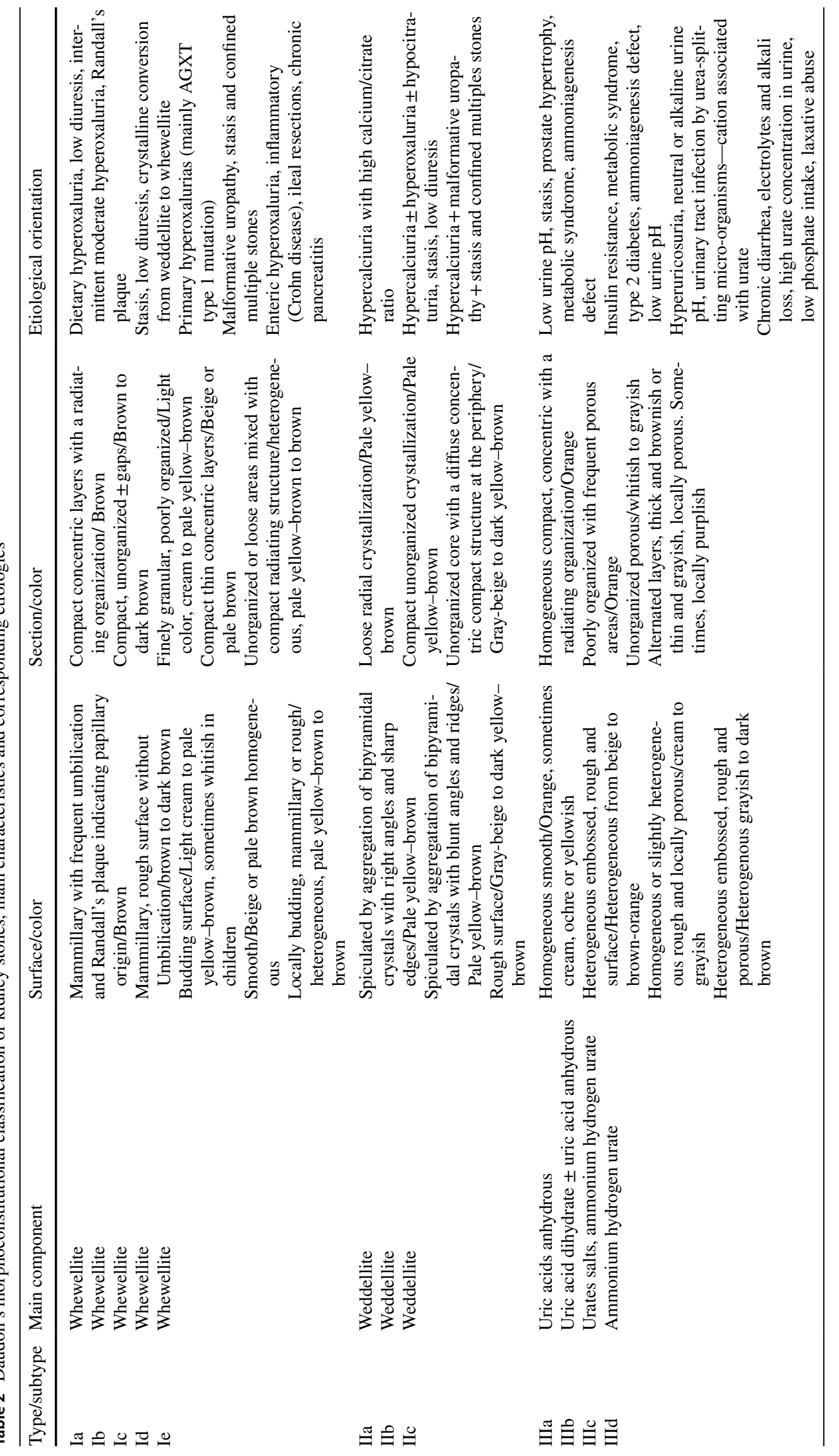




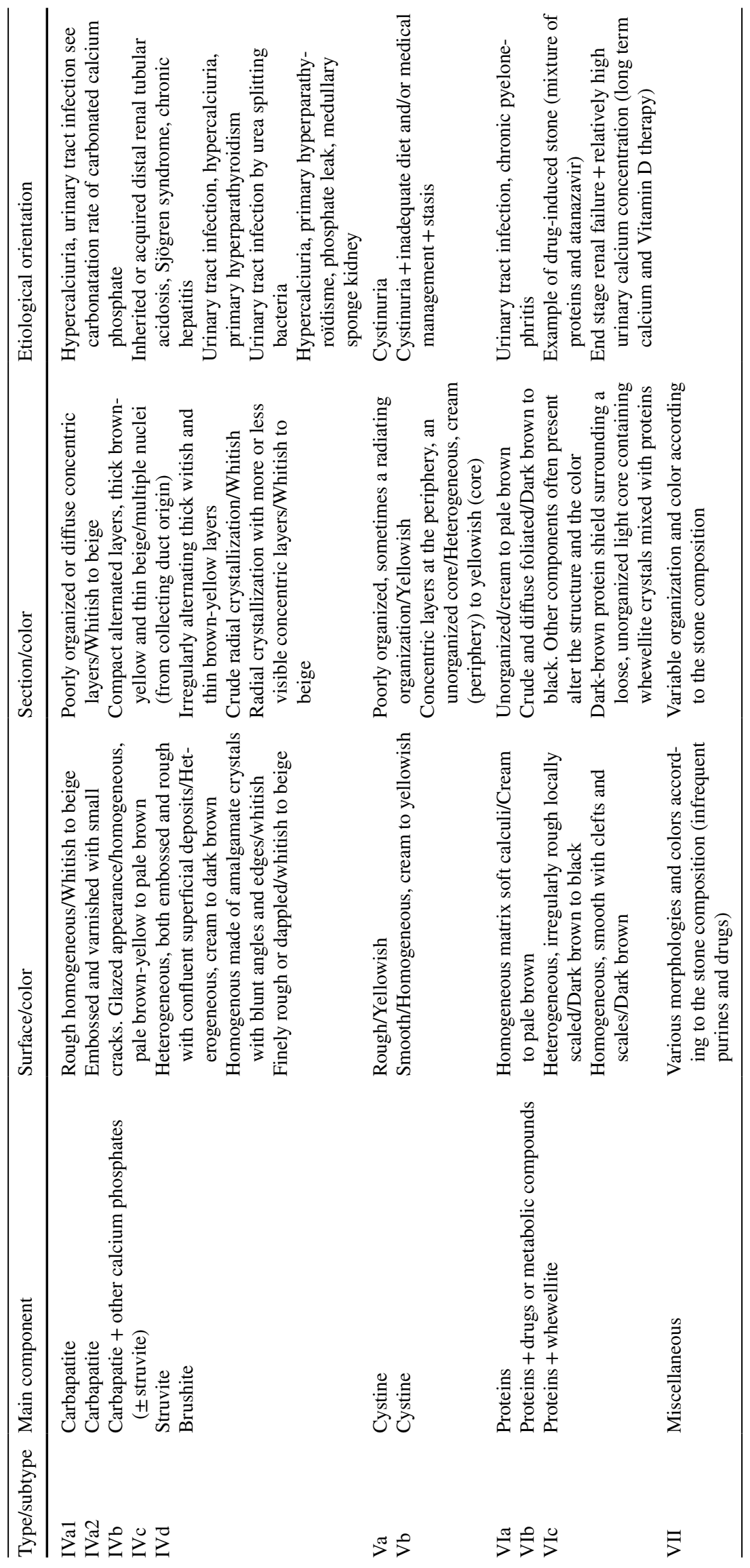


present as five different morphologies: among them, type Ia is often related to moderate hyperoxaluria due to low diuresis or intake of oxalate-rich food. By contrast, type Ic is pathognomonic of genetic heavy hyperoxaluria [38] and type Ie is a marker for enteric hyperoxaluria [34]. Sequential analysis may reveal changes with time in the factors involved in stone formation.

Prof Khashayar Sakhaee from the United States underlined the association between changes in kidney stone composition, with the varying demographics and biochemical profiles in a retrospective study in the Unites States from 1980 to 2015 involving 1516 KS patients. This study showed the proportion of UA stones increased from 7 to $14 \%$ [8]. The proportion of females with KS increased over time but the increase in females was more significant among calcium stone formers. Age and body mass index increased with time in both UA and calcium stone formers [39, 40]. However, UA stone formers were consistently older and had a higher body mass index and lower urinary $\mathrm{pH}$ than calcium stone formers [8]. Hyperuricosuria itself or concomitantly with hypocitraturia, hyperoxaluria and hypercalciuria could lead to hyperuricosuric calcium nephrolithiasis [41]. A separate retrospective study of $2132 \mathrm{KS}$ patients from Europe demonstrated that obese and overweight KSF exhibited higher urinary UA, urinary sodium, urinary calcium and significantly lower urinary $\mathrm{pH}$ [9]. In addition to increased prevalence of metabolic syndrome in the past decades, global warming and greater urbanization are predicted to contribute to increased risk of nephrolithiasis in the future [42]. Finally, the protective impact of dietary approaches to KS prevention is more apparent in single stone formers, whereas anti-lithogenic drugs are more effective for recurrent KSF [43].

\section{Cell biology of nephrocalcinosis and nephrolithiasis}

Considering the increased incidence of KSD Benjamin Vervaet, cell biology researcher from Belgium presented the interactions between crystals and renal tubular epithelial cells, and the role of the renal tubular epithelium both in the onset and outcome of early stages of KSD. Like any other bio-mineralization process, nephrocalcinosis and nephrolithiasis are manifestations of a complex interplay between crystals physicochemical characteristics and cell biology [44]. This century, it has become clear that nephrocalcinosis and nephrolithiasis are to be considered two independent entities. In depth microscopic and histopathologic research was crucial to differentiate between intratubular and interstitial nephrocalcinosis. On the one hand, intratubular nephrocalcinosis develops as a consequence of phenotypical changes of the renal tubular epithelial cells, which, due to prior injury, gain crystal-binding properties [45]. On the other hand, interstitial nephrocalcinosis starts as a de novo crystal formation process in the interstitium and is thought to be the result of local patho-physiological disturbances in proper ion and/or acid-base handling [46]. Both forms of nephrocalcinosis can progress to nephrolithiasis, however only under certain specific conditions. In addition, being evolutionary challenged, the kidney displays several crystallization defense mechanisms. At least in the condition of intratubular nephrocalcinosis, kidney is even capable of actively removing and dissolving retained crystals in a celldriven process [47]. Although it is clear that the kidney has still not revealed all its cell biological secrets, concerted research actions has led to the development of solid etiological concepts.

\section{Determinants of Randall's plaque formation}

The mechanism of heterogeneous nucleation at the tip of the renal papilla that give birth to $\mathrm{CaOx}$ stones was detailed by Prof Emanuel Letavernier from Service des explorations fonctionnelles, Tenon Hospital in Paris, France. He underlined that the genetic and environmental determinants of Randall's plaque formation are still partly described.

Indeed, KS were for the first time described to originate from calcium phosphate plaques growing in the interstitial tissue, breaking the urothelium and then promoting monohydrate $\mathrm{CaOx}$ crystal aggregation at their contact over 6 decades ago. The development of endoscopic procedures allowing plaque visualization renewed interest in Randall's plaque. In parallel, a dramatic increase in the proportion of $\mathrm{CaOx}$ stones grown on Randall's plaque during the past decades has been reported in France [48].

Hypercalciuria is probably a major risk factor for Randall's plaque formation. Increasing sensitivity to vitamin D in KSF presenting with Randall's plaque has been proposed $[49,50]$. Calcification inhibitors might be essential to prevent Randall's plaque development [50,51]. The identification of environmental factors and genetic polymorphisms promoting Randall's plaque formation have emerged as essential to eventually prevent or slow down plaque formation in predisposed children and young adults [52].

\section{Pathology of crystals-induced nephropathy}

Sustained exposure of tubular epithelium to crystals induce a lesion classified as crystal induced nephropathy or crystalline nephropathy $(\mathrm{CN})$, term applied to patterns of renal injury sharing the distinctive finding of crystals within tubules and/or interstitium. Crystal nephropathy is not only related to the crystals deposition as detailed Prof Isabelle Brochériou from Pathology Department at Pitié-Salpêtrière 
Hospital, Sorbonne Université and INSERM Unit U1155 in Paris, France. Indeed, based on the clinical setting in which they are formed, or on the composition of the crystals, $\mathrm{CN}$ is divided into the following 4 categories: (1) $\mathrm{CN}$ related to dysproteinemia, (2) drug-induced $\mathrm{CN}$, (3) $\mathrm{CN}$ related to calcium deposition, and (4) other metabolic and genetic $\mathrm{CN}$ forms.

The dysproteinemia-related $\mathrm{CN}$ includes light chain cast nephropathy, also known as myeloma cast nephropathy, which is the most common dysproteinemia-related renal disease $[53,54]$. Crystalline nephropathy may develop during the use of drugs (ceftriaxone [55]), sulfadiazine [56], acyclovir [57], triamterene [58], atanazavir [59], and others that are excreted by the kidney (see details in recent review [60]). Calcium crystals $\mathrm{CN}$ is characterized by abundant tubular and interstitial deposits of calcium phosphate or $\mathrm{CaOx}$ crystals, easily distinguished by their tinctorial properties. Hypercalcemia is the most common condition associated with subsequent nephrocalcinosis. Enteric hyperoxaluria is frequently found in $\mathrm{CaOx}$ nephropathy, which can also be seen in severe hereditary enzymatic defects known as the primary hyperoxaluria [61]. Some inherited (cystinosis, 2,8-dihydroxyadenine deficiency, primary hyperoxaluria) or acquired metabolic disorders are responsible for crystalline nephropathies [62-64]. Careful clinical-pathologic correlation with concomitant identification of urine crystals
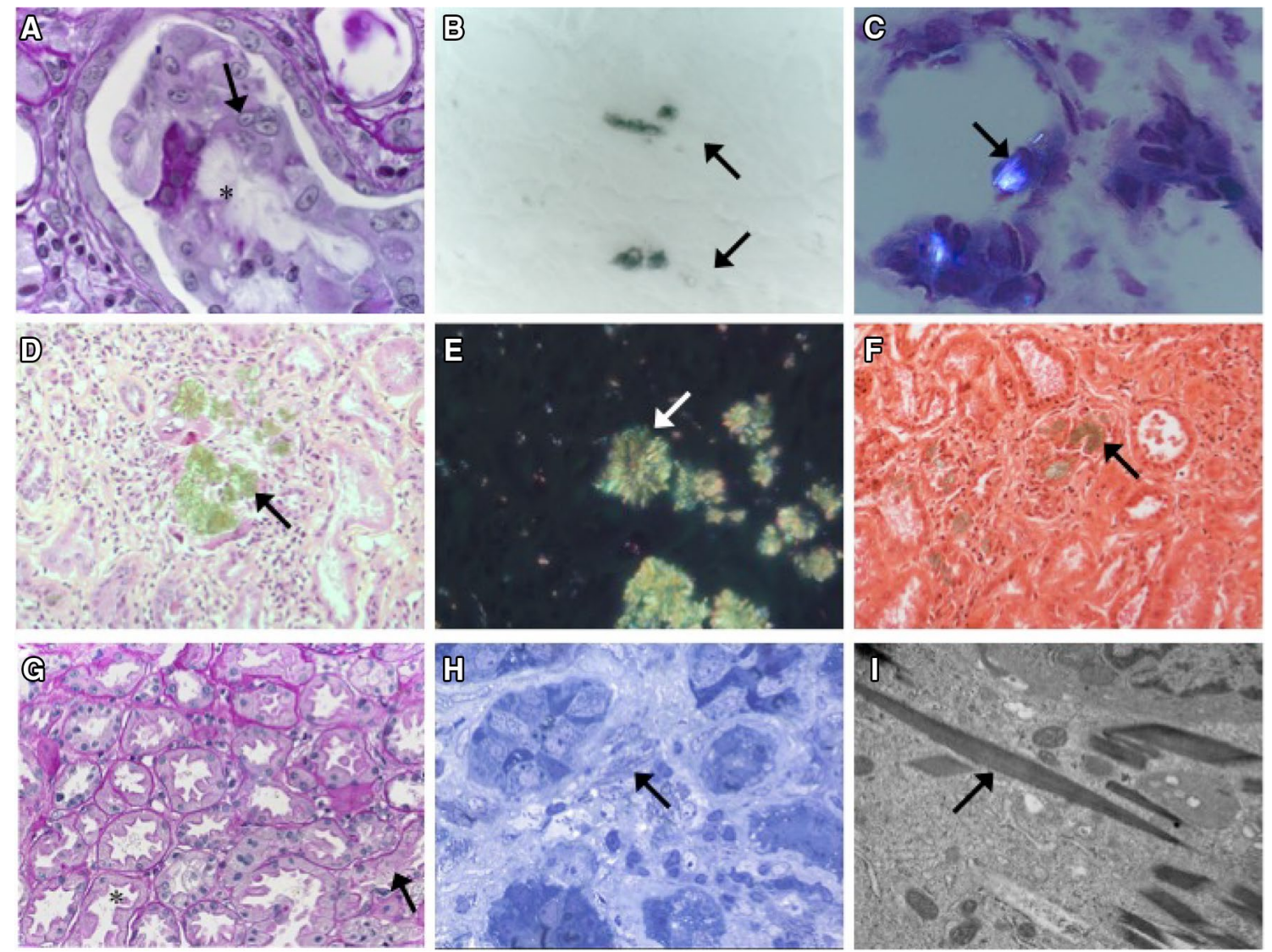

Fig. 1 Representative photomicrographs of crystalline nephropathies. Atazanavir-induced nephropathy: a Foreign-body type reaction (arrow) surrounding the crystal (star). PAS staining, original magnification $\times 200$. b Cristals (arrows) present on typical frozen section without staining, original magnification $\times 400$. c Birefringent, intratubular and intracellular crystals observed under polarized light microscopy analysis, original magnification $\times 400$. Crystalline nephropathy due to 2,8-dihydroxyadeninuria: d Several yellowbrownish crystals (arrow) within the cytoplasm of tubular epithelial cells and foreign-body type reaction within interstitium surrounding the crystal aggregates. Hematoxylin \& eosin staining, original magnification $\times 400$. e Polarized light microscopy showed the crystals to be strongly birefringent, demonstrating a radial orientation with a variable appearance, including needle, ring- and spherically-shaped aggregates (so-called Maltese cross pattern was not observed in this case). Original magnification $\times 400$. $\mathbf{f}$ Crystals are negatives on Van Kossa staining used for identification of calcium deposits, Original magnification $\times 200$. Monoclonal gammopathy of renal significance: g Proximal tubular lesions were seen with focal atrophy (star) and brush border disappearance (arrow). PAS staining, original magnification $\times 200$. h Crystals were detected in the cytoplasm of interstitial histiocytes (arrow) on toluidine blue staining of semithin sections. i Numerous needle-shaped crystals (arrow) in the cytoplasm of altered epithelial cells (crystalline inclusions were observed in the cytoplasm of proximal tubular cells, not shown). Electron microscopy study. Kindly provided by Prof Isabelle Brochériou from Pathology department, Pitié-Salpêtrière hospital, INSERM Unit U1155, Paris, France 
(cristalluria) is fundamental in the interpretation of $\mathrm{CN}$ etiology $[65,66]$. Adequate identification of the causative pathological condition(s) improves the correctness of diagnostic (Fig. 1) allowing a more personalized therapeutic approach that is essential to reduce the risk of kidney function decline $[62,64,66]$.

\section{Kidney stones as a multi-systemic illness}

If uncontrolled, CN leads to progressive loss of glomerular filtration rate and development chronic kidney disease (CKD). This long-term complication of KSD was presented by Prof Agnieszka Pozdzik from Kidney Stone Clinic, Nephrology and dialysis clinic at Hospital Brugmann, Université Libre de Bruxelles in Brussels, Belgium.

Considering that $\mathrm{CKD}$ has become a global public health problem with serious social and economic effects from premature morbidity to death, nephrologists are attentive to identify all possibly treatable CKD risk factors, and KSD is one of them [67].

Indeed, growing evidence demonstrates a consistent relationship between nephrolithiasis and the development of CKD, and leading to end-stage renal disease (ESKD) in more than 3\% of cases [68-70]. Moreover, recent epidemiological studies have shown the association of KSD with cardio-vascular disorders, arterial hypertension, obesity, diabetes mellitus, metabolic syndrome that are well-recognized risk factors for CKD (Fig. 2) [71]. Regardless of the associated co-morbid conditions, KSD has been shown to be an independent risk factor in the development of CKD [15]. Definitely, KSF have nearly twice-risk to develop CKD compared with patients without stones. Urolithiasis and its

Kidney stones disease is a systemic metabolic disorder

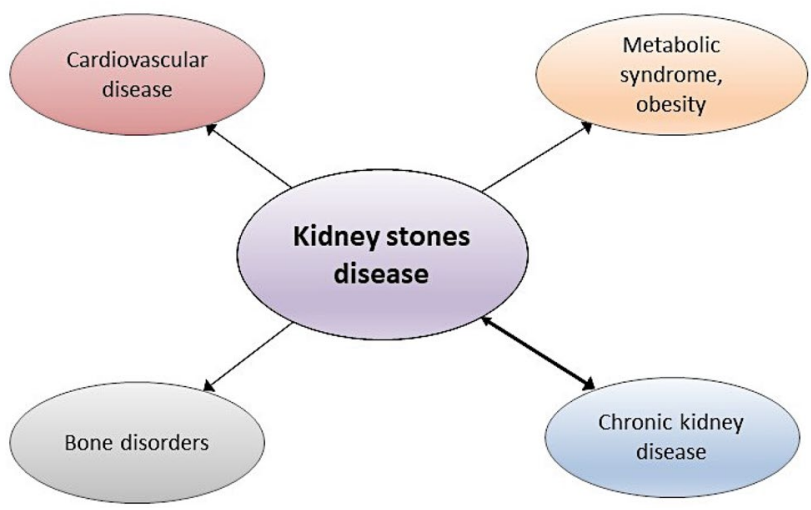

Fig. 2 Interrelationships between kidney stones disease, cardiovascular disease, systemic metabolic disorders, bone metabolism and chronic kidney disease complications or conditions associated with kidney stones have been reported in $5.1 \%$ of all ESKD cases [72].

Other risk factors associated with CKD identified in $\mathrm{KSF}$ include: existing kidney functional impairment, recurrent urinary tract infections with kidney stones of particular compositions including struvite, UA stones, symptomatic stones, solitary kidney, neurogenic bladder, renal or urinary tract malformations and ileal diversion, malabsorptive bowel conditions and some monogenic diseases responsible for nephrolithiasis and/or nephrocalcinosis, especially in children (Table 1) [73].

Given the risk of KS recurrence, high morbidity, the necessity of endo-urological or surgical interventions, early diagnosis and specialized management of KSD is indicated [74]. Awareness is essential to rapidly identify the pro-lithogenic metabolic abnormalities, assess the coexistence of renal and/or cardiovascular complications with the aim of controlling KSD and slowing down the CKD progression with adequate treatment $[75,76]$. At the present time the evaluation of the global risk of developing CKD/ESKD and of related metabolic disorders during the workup of patients with KS is mandatory (Fig. 3). In addition, the ultrasound scans exploration of $\mathrm{KS}$ and related complications such as obstructive nephropathy or urinary tract infection need to be adapted case by case during the follow [77].

\section{Calcium metabolism and kidney stones}

In their presentations, Dr. Naim Maalouf and Dr. Khashayar Sakhaee from the Department of Internal Medicine and the Charles and Jane Pak Center for Mineral Metabolism and Clinical Research at the University of Texas Southwestern Medical Center, in Dallas, Texas, USA, reviewed normal calcium homeostatic mechanisms and pathophysiologic mechanisms underlying hypercalciuria. Intrinsic determinants of urinary calcium excretion include factors that impact the filtered load of calcium (via intestinal calcium absorption and bone formation/ resorption), and others that alter renal calcium handling at various segments of the nephron. Extrinsic factors that alter calcium handling involve dietary and other lifestyle factors (including intake of calcium, sodium, animal proteins, etc..), and medications that impact calcium metabolism and ultimately the risk of nephrolithiasis.

Calcium KSD is the second most prevalent kidney disease after arterial hypertension. Approximately $80 \%$ of calcium kidney stones are $\mathrm{CaOx}$, with a small percentage $(15 \%)$ of calcium phosphate. The pathophysiologic mechanisms for calcium KS are complex and diverse [78, 79]. However, both hypercalciuria and hyperoxaluria play a major role in the formation of calcium oxalate stones. Hypercalciuria is a heterogeneous disorder and is commonly due to enhanced 
Fig. 3 Proposed evaluations for diagnosis and management of patients with kidney stones. $C K D$ chronic kidney disease, $H T A$ arterial hypertension, $K S$ kidney stone, $K S D$ kidney stone disease

\section{Diagnosis and management of patients with kidney stones}

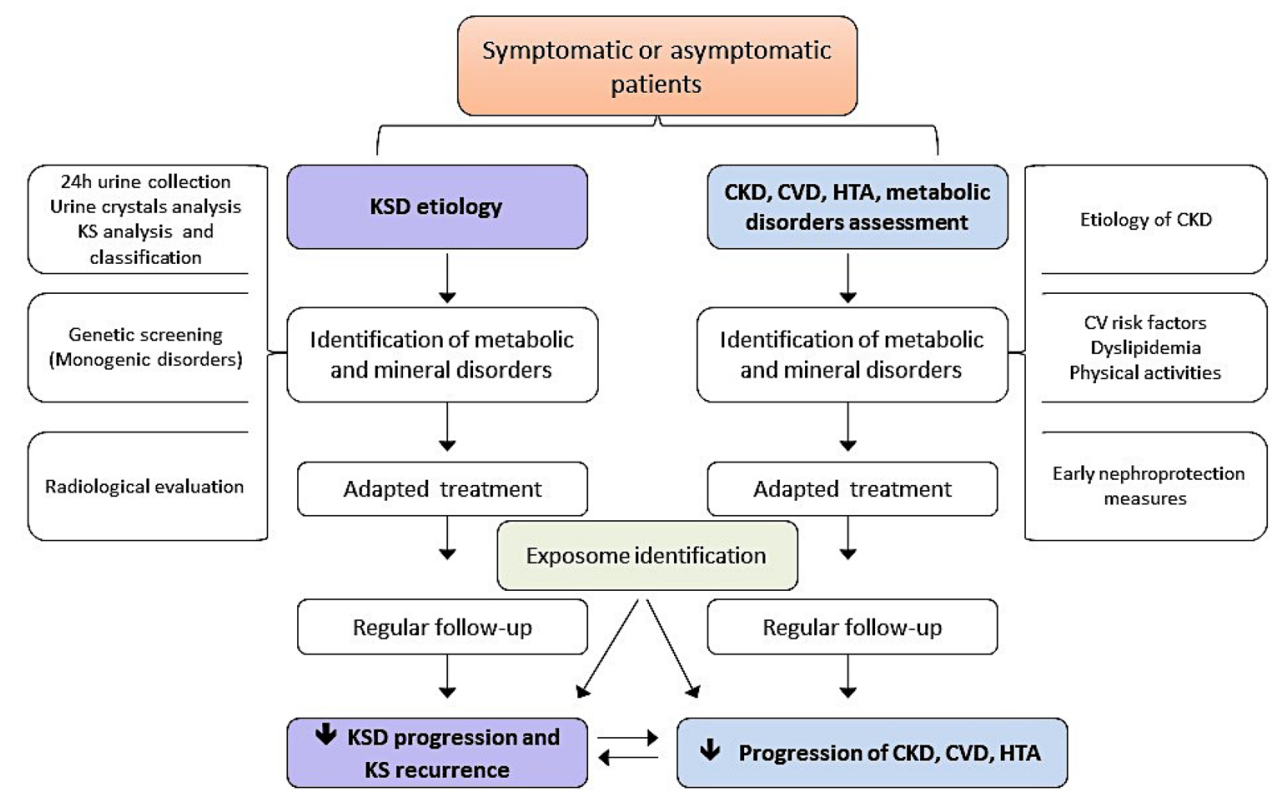

intestinal calcium absorption which has been demonstrated to be $1,25(\mathrm{OH})_{2}$ vitamin D-dependent or independent [80]. A previous study showed that absorptive hypercalciuria is due to increased production of $1,25(\mathrm{OH})_{2} \mathrm{D}$. However, until recently the underlying mechanism of overproduction of $1,25(\mathrm{OH})_{2} \mathrm{D}$ was not fully elucidated. Recently, loss-offunction mutations in CYP24Al in patients with idiopathic infantile hypercalciuric nephrolithiasis has been shown to be a responsible mechanism in a subset of this population [81].

With increasing body mass index over the past $3-1 / 2 \mathrm{dec}-$ ades, urinary oxalate excretion has gradually and significantly increased [8]. One important underlying mechanism has been linked to differences in the decreasing prevalence of Oxalobacter formigenes (OF) colonization among patients with recurrent calcium stone disease [82]. This gram-negative obligate anaerobe bacterium found in gastrointestinal tracts of humans uses oxalate as its sole source of energy [83]. A metabolic study performed in OF colonized and non-colonized stone formers demonstrated significantly higher urinary oxalate among the non-colonized stone-forming population. In addition, an inverse relationship was detected between the number of stone episodes and OF colonization rate [84]. Improved understanding of this pathogenetic pathway will open the door to the new pharmacological approaches using probiotic therapy with $\mathrm{OF}$, oxalate degrading enzymes, and/or recombinant proteins to upregulate of oxalate secretion into the intestinal lumen. The link between overweight, and obesity with alteration in colonization with OF is in part related to the risk of hyperoxaluria in obese subjects. Another potential mechanism has been attributed to the involvement of inflammatory processes caused by obesity resulting in increasing intestinal permeability and enhanced oxalate absorption.

Calcium stone formers are known to exhibit an exaggerated postprandial rise in urine calcium excretion compared with non-stone-forming subjects, and insulin has been proposed to mediate this difference. However, the rise in urinary calcium associated with euglycemic hyperinsulinemia has shown not to be different between KSF and non-stoneforming controls. Thus, insulin is unlikely to play a role in the pathogenesis of hypercalciuria in this population. Lastly, a short-term study has shown that mechanism(s) other than acid load accounts for hypercalciuria induced by a high protein diet. This study will open new insights into the potential role of aromatic amino acids in regulating calcium sensor in gastrointestinal tract and kidney in the pathogenesis of protein-induced hypercalciuria $[85,86]$.

\section{Primary hyperparathyroidism: diagnosis and treatment}

The prevalence of primary hyperparathyroidism (HPT) varies between 1 and 20/1000 [87] underlined Prof JeanJacques Body, from Internal Medicine department at Brugmann Hospital, and head consultant for Bone diseases and endocrinology at Institute Bordet (Cancer Centre at the «Université Libre de Bruxelles», Brussels, Belgium).

HPT is nowadays most often asymptomatic and the diagnosis is made by chance or done during the workup of calcium nephrolithiasis or osteoporosis [88]. The incidence of nephrolithiasis has been considerably lowered 
but is still the most frequent complication of HPT (17\%) whereas osteoporotic fractures are now present in less than $2 \%$ of the cases. Hypercalcemia and an elevated parathyroid hormone $(\mathrm{PTH})$ concentration, or at least a PTH level in the upper part of the normal range, generally point to a diagnosis of HPT. Additional tests include an evaluation of renal function, vitamin D measurement, determination of 24-h urinary calcium and bone densitometry [89].

Besides symptomatic HPT, recent recommendations for surgery include age less than 50, serum calcium at least $1 \mathrm{mg} / \mathrm{dL}$ above the upper limit of normal, calculated creatinine clearance $<60 \mathrm{ml} / \mathrm{min}, 24-\mathrm{h}$ urinary calcium higher than $400 \mathrm{mg} / \mathrm{day}$ (or $10 \mathrm{mmol} / \mathrm{day}$ ), and increased stone risk by biochemical stone risk analysis, presence of nephrolithiasis or nephrocalcinosis, and clinical or confirmed osteoporosis $[90,91]$. Parathyroid scintigraphy coupled with computed tomography is the best preoperative localization technique. In the hands of an experienced surgeon, the success rate of elective surgery is $96-99 \%$ and the rate of permanent complications is lower than 1-2\% [92].

\section{Type 2 diabetes and calcium nephrolithiasis}

An increased prevalence of nephrolithiasis reported in patients with type 2 diabetes has been approached by $\operatorname{Pr}$ Michel Daudon. Because insulin resistance, characteristic of the metabolic syndrome and type 2 diabetes, results in lower urine $\mathrm{pH}$ through impaired kidney ammoniagenesis, and since a low urine $\mathrm{pH}$ is the main factor of UA stone formation, it was hypothesized that type 2 diabetes should favor the formation of UA stones [93-96]. An abundant literature has extensively confirmed that around 30 to $40 \%$ of type 2 diabetic stone formers produce UA stones. While the prevalence of UA stones was significantly increased in French cohort of diabetic patients, Pr Daudon conversely found a significant decrease in calcium phosphate stones and weddellite stones in such patients [93]. By contrast, the proportion of whewellite calculi was not reduced, which suggests that hyperoxaluria could be another metabolic factor involved in stone formation in type 2 diabetes [97]. In addition, the morphology of whewellite stones suggest highs levels of urinary oxalate. Actually, urinary oxalate excretion was found significantly increased in diabetic patients and it was recently reported that glyoxylate, one of the main precursor of oxalate synthesis, was early increased in blood of type 2 diabetic patients [98, 99]. The proposed link between glyoxylate and type 2 diabetes could be AGXT2, an hepatic enzyme that may be downregulated by loss of function of HNF4 $\alpha$ (hepatic nuclear factor $4 \alpha)$ [100].

\section{Nephrolithiasis from vitamin D and calcium supplementation}

Calcium and vitamin D supplements are widely used for the prevention and treatment of osteoporosis. These supplements significantly increase urinary calcium, potentially predisposing to calcium nephrolithiasis said Dr Naim Maalouf. In several observational and randomized prospective studies, including the large Women's Health Initiative randomized clinical trial, supplemental calcium and vitamin D significantly increased the incidence of nephrolithiasis [101]. Calcium supplement type (calcium carbonate vs. calcium citrate), dose, and timing of intake, all appear to influence KS risk. In contrast to calcium supplements, higher dietary calcium intake appears to lower the risk of kidney stone formation in several observational studies [102-104]. The impact of vitamin D supplementation (without calcium) has been studied in small prospective studies and found to be safe for the average KSF with vitamin D deficiency [105]. However, a subset of calcium stone formers may exhibit worsening hypercalciuria upon vitamin D supplementation [106]. In his presentation Dr Maalouf reviewed the epidemiology and pathophysiologic mechanisms by which calcium and vitamin D supplements impacts nephrolithiasis risk, and outlined a framework to employ when considering calcium and/or vitamin D supplementation in nephrolithiasis patients (Table 3).

\section{Calcium oxalate stone morphology and urine biochemistry in malabsorptive bowel diseases}

In bowel diseases, a malabsorption syndrome may result from intestinal diseases or frequently from gastric bypass surgery prescribed as treatment of morbid obesity [107]. The prevalence of $\mathrm{CaOx}$ stones and the renal prognosis of patients undergoing a bariatric surgery or affected by bowel diseases is a matter of concern nowadays underlined Prof Emmanuel Letavernier. Indeed, low diuresis, resulting from reduced water intake and water loss (diarrhea), is a common risk factor of kidney stones. Patients with colon resection and ileostomy form uric acid stones, attributed to bicarbonate loss in the ileostomy and low urine $\mathrm{pH}$. Patients with malabsorption syndrome and functional colon are affected by calcium oxalate stones due to a heavy urinary concentration in oxalate (enteric hyperoxaluria) $[108,109]$. Free fatty acids resulting from malabsorption chelate calcium ions in the intestinal lumen and oxalate ions are therefore no more bound to calcium ions and absorbed through the colonic lumen [110]. Kidney stones 
Table 3 Considerations in special populations regarding risks associated with calcium and vitamin D supplementation

\begin{tabular}{|c|c|}
\hline Population & Consideration/risk \\
\hline Menopause, elderly & Impaired intestinal calcium absorption \\
\hline Achlorhydria, malabsorption & $\begin{array}{l}\text { Impaired calcium absorption. Calcium from natural sources are preferred } \\
\text { over calcium supplementation. Calcium citrate recommended as calcium } \\
\text { supplement given its optimal intestinal bioavailbility and it may slightly } \\
\text { increase urinary citrate excretion }\end{array}$ \\
\hline Obese & Higher baseline bone mineral density, but also CV risk \\
\hline Advanced CKD & Vascular calcification with greater calcium supplementation \\
\hline Genetics/Race & $\begin{array}{l}\text { Lower urine calcium in Blacks vs. Whites } \\
\text { Risk of hypercalciuria/stones with calcium and/or vitamin D supplementation } \\
\text { in idiopathic infantile hypercalcemia (mutations in } C Y P 24 A 1, S L C 34 A 1 \text { ) }\end{array}$ \\
\hline $\begin{array}{l}1 \alpha \text { hydroxylase over-activity (primary hyperparathyroidism, } \\
\text { sarcoidosis, others...) }\end{array}$ & Risk of hypercalciuria/stones with calcium and/or vitamin D supplementation \\
\hline "Absorptive hypercalciuria" & Risk of hypercalciuria/stones with calcium and/or vitamin D supplementation \\
\hline
\end{tabular}

Generally, dietary sources of calcium are preferred over supplemental (tablet) in patients whose calcium intake is below the recommended daily intake. The following additional considerations/risk factors should be considered

resulting from enteric malabsorption are typically made of calcium oxalate monohydrate and have a specific morphology: light brown aspect and poorly organized section (type Ie). This morphology is specifically associated to massive hyperoxaluria and high oxalate/calcium ratio in the urine [34].

\section{Urological management of kidney stones}

Nowadays there are three most used surgical procedures in the treatment of urinary stones which are shockwave lithotripsy, ureteroscopy and percutaneous nephrolithotomy.

Extracorporeal shock wave lithotripsy (ESWL) is a minimal invasive treatment based on shockwaves that are focused on a target (the stone). The success rate of ESWL said Dr Johanna Noels from Urology department, University hospital Brugmann in Brussels, Belgium, is influenced by the stone localization and anatomical factors of the kidney and ureter, the hardness of the stone which is estimated by measurement of Hounsfield units (HU) on CT-images, (exception cystine stones with low HU, but very resistant), the stone size and patient factors (obesity) and preference of patients [111].

Ureteroscopy is nowadays a common procedure to treat ureteral and kidney stones said Dr Carl Van Haute from Urology department, University hospital Brugmann in Brussels, Belgium. This minimal invasive endo-urological procedure has several advantages such as high stone-free rate (SFR) with a minimal risk of complications. Indications of ureteroscopy were highlighted. Semi-rigid ureteroscopy is used to treat a ureteral stone, mostly in the middle and lower parts of the ureter, whereas flexible ureteroscopy can be used to treat any ureteral stone, as well as kidney stones (upper, mid and lower pole stones). Stone size, stone location and degree of impaction can influence SFR. Stone composition on the other hand won't affect SFR but will lead to longer operative times.

Whether a stone should be completely dusted to achieve the highest SFR, or fragmented with successive extraction, is still controversial. Complication rate is very low (3.5\%) and complications are mostly minor. Severe complications, such as ureteral trauma (0-2\%) and urinary sepsis with multi organ failure are rare $(0.1 \%)$.

Percutaneous nephrolithotomy (PCNL) is the oldest minimal invasive treatment strategy to treat large kidney stones. PCNL can be used to treat large kidney stones $(>10 \mathrm{~mm})$, staghorn stones, infection stones, and large or impacted proximal ureteral stones. In case of a retrograde inaccessible urinary derivation (ileal conduit, neobladder, continent urinary reservoirs, etc.), PCNL is a treatment option for kidney and ureteral stones. Among minimally invasive techniques for kidney stones (ESWL/ URS), PCNL has definitively the highest SFR for large stones $(>2 \mathrm{~cm})$.

When performing PCNL, obtaining adequate renal access is the key factor. Different imaging methods are used such as ultrasound, fluoroscopy, CT and endoscopy guidance.

PCNL can be performed in prone or supine position. Both positions have benefits and drawbacks, the choice for either position depends on the surgeon's experience, patient-related factors and stone burden.

Modern PCNL techniques include miniaturization of the surgical devices, aiming at less blood loss, less renal damage, and less pain. Standard, mini, ultra-mini, supermini, mini-micro and micro techniques have been described, all with varying tract sizes ( $<5$ french up to $>22$ french). Smaller tracts lead to less blood loss, less pain and shorter 
hospital stays, but have a negative impact on the operative time.

Complications in PCNL can occur. Infectious complications (10\%) and bleeding (7\%) are the most frequent. Injury to nearby organs (pleura, liver, spleen, colon, etc...) are rare (1\%) and can sometimes need to be conservatively managed.

\section{Epidemiology of urolithiasis in Belgium according to Daudon's morphoconstitutional classification}

Increasing evidence underlines that morphoconstitutional (MC) analysis is a clue to the pathogenesis of KS and guides preventive and therapeutic specific interventions.

Dr Romy Gadisseur from Clinical Chemist, EuSpLM, Laboratories "Emergency, Allergy, Urolithiasis" at University Hospital of Liège and Vincent Castiglione Ph.D. student at the Clinical Chemistry department of University Hospital of Liège presented their results of distribution of stone composition in Province of Liège (Belgium) according to age and sex [112]. They retrospectively reviewed 1869 urinary stones analyzed between 2010 and 2013 at the laboratory of the CHU of Liège (Belgium). Samples were assessed by infrared spectroscopy, and morphology was used to classify KS in MC types according to Daudon's classification. Among 1869 stones, $69.2 \%$ affected men. The peak prevalence was observed between 50 and 60 years of age in both genders. The main constituent was calcium oxalate monohydrate (54.4\%), mainly organized as type Ia (94\%). Calcium oxalate dihydrate was found in $19.8 \%$ samples, with an equal distribution between types IIa and IIb. Uric acid was the 3 rd most frequent constituent in men (10.8\%), instead of phosphates in women (26.6\%). Urinary infection may be the main cause of stone formation in $6 \%$ of patients. Multiple morphological types were concomitantly identified in $49.3 \%$ of stones. With aging, the proportion of calcium oxalate dihydrate stones decreased, while that of calcium oxalate monohydrate and uric acid increased in both genders.

Prof Fredric Cotton and Agnieszka Pozdzik presented data from retrospective study applying Daudon's MC classification based on stereomicroscopy and infrared spectrophotometry analysis of KS inform the center in Brussels. The analysis was carried out on 5480 samples sent to the laboratory between 2007 and 2013. Among 5027 stones formers, $3549(71 \%)$ were men and $1478(29 \%)$ were women. The main compound observed was calcium oxalate (whewellite $52 \%$, weddellite $23 \%$ ), followed by calcium phosphate stones (carbapatite 6.8\%), uric acid stones (anhydrous uric acid $9.1 \%$ ), and struvite (2.1\%). In $40 \%$ of the cases, one single compound accounted for more than $90 \%$ of the composition. Two compounds or more were found in $28 \%$ and $31 \%$ of KS, respectively. The most common associations were weddellite-whewellite-carbapatite (15\%), weddellitewhewellite (12.4\%) and weddellite-carbapatite (6.1\%).

Type Ia was the most common in whewellite stones (91.6\%) and type IIa (73\%) followed by type IIb (25\%) in weddellite stones. Uric acid stones corresponded mainly to type IIIa (52\%) and IIIb (46\%). Carbapatite defined as type IVa was found in $42 \%$ and as type IVb in $32 \%$. Whewellite and weddellite KS predominated in men in all age groups with the highest prevalence between 40 and 50 years. The prevalence of uric acid KS was higher in men peaked between 60 and 70 years. Struvite and carbapatite KS were mostly observed between 40 and 50 in both genders but more frequently in women between 20 and 60 years. To our knowledge, the epidemiology based on M-C analysis reported here has been performed in the largest cohort of KS available in Belgium. Presented data suggests that the leading metabolic disorders involved in lithogenesis in the Brussels population are likely intermittent hyperoxaluria leading to stones of type Ia and hypercalciuria associated with stones of type IIa.

\section{Medical measures for the secondary prevention of nephrolithiasis}

Kidney stone disease without treatment is a recurrent illness that represents a major health burden across the globe with associated economic costs. A conservative approach is the key management in all KSF. Pharmacological treatment is indicated in recurrent stone-forming populations [113].

High oral fluid intake must be consumed in all KSF to reduce urinary saturation with respect to stone-forming salts [114]. The consumption of fructose- and phosphoric acidbased soft drinks may increase the risk of KS formation.

A dietary intervention consisting of low sodium ( $\leq 100 \mathrm{mEq} /$ day), low animal protein (50 to $60 \mathrm{~g} /$ day) with normal calcium intake $(1200 \mathrm{mg} /$ day $)$ significantly reduced risk of KS recurrence when compared to low dietary calcium intake (400 mg/day) [113]. However, the role of the low animal protein intake alone on reducing stone recurrence has been shown only in one study. Similarly, the evidence for the role of dietary fiber, low sodium, calcium and purine intake in the recurrence of KS remains circumstantial.

Pharmacological treatment of calcium KSF includes alkali and thiazide diuretics $[115,116]$. Alkali treatment is recommended in recurrent calcium oxalate and calcium phosphates as well as UA kidney stone formers, with hypocitraturia or normal urine citrate, distal renal tubular acidosis, chronic diarrhea, drug or diet-induced hypocitraturia. Thiazide diuretics are commonly used in those with hypercalciuric nephrolithiasis. It is preferable to combine potassium alkali treatment with thiazide than potassium chloride supplementation in raising urinary citrate excretion [116]. 
Allopurinol was shown to be effective in lowering the risk of calcium KS. The effectiveness of the magnesium in reducing the risk of stone has not yet been established.

\section{Challenges in the diagnosis of kidney stones}

With careful evaluation and management, the great majority of KS are preventable. Despite vast developments in the radiological, morphoconstitutional and biochemical analyses in the past 5 decades, the incidence, costs, and morbidity of nephrolithiasis are rising, and persistent challenges hinder the optimal diagnosis and KSD management. In particular, recent advances in imaging techniques to identify stone composition and/or extent of Randall's plaque in vivo are promising. Challenges in biochemical analyses of individual urinary parameters, and in computer-based assessment of urinary saturation indices, include a significant overlap in these parameters between stone formers and non-stone formers. Cut-off values for predicting stone recurrence are currently investigated. The morphoconstitutional analysis of KS needs to be more frequently used as it can be very helpful in the evaluation of KS etiology considering the fact the KS contain the fingerprints of metabolic disorders.

\section{Conclusions and outcomes}

The symposium on kidney stones and mineral metabolism is currently one of the few dedicated kidney stones meetings to be held internationally on a biannual basis. In 2017, the first meeting brought together clinical and basic researchers, pathologists, nephrologists, urologists and biologists. This model demonstrates how clinical and research collaboration should be facilitated, as it brings together worldwide recognized experts in the diagnosis and treatment of nephrolithiasis. This is of greatest importance for patients and families, specifically those with inherited KSD, as well as to encourage new recruitment of physicians interested in KSD pathophysiology. The symposium provided the available knowledge in KSD but also the future direction in promoting the new advancements in the field.

Acknowledgements We are thankful the Direction department (Profs Jean-Marie De Meyer and Jean-Bernard Gillet, and Mr Fancis de Drée) of Brugmann hospital, Brussels, Belgium for the hosting commodity of the symposium. Our particular acknowledgements go to Mrs Isabelle Poplement and Mrs Leslie Leclercq for her deep involvement in the practical organization of symposium. We greatly appreciate the help Mrs Isabelle Martin, Joelle Watticant and Françoise Devillers from Ergotherapy department at CHU Brugmann.

Funding This symposium was sponsored by scientific grants (MDeon Visa 17/V2/10119/005925) from Nippro Belgique, Amgen Belgique,
Baxter Belgique, Vifor Fresenius Medical Care Renal Pharma Belgique, BellcoMedtronic, Menarini Belgique and BioHealth Italy.

\section{Compliance with ethical standards}

Conflict of interest On behalf of all authors, the corresponding author states that there is no conflict of interest regarding this article's content.

Ethical approval All procedures followed were in accordance with the ethical standards of the responsible committee on human experimentation (institutional and national) and with the Helsinki Declaration of 1975. This article does not contain any studies with animal subjects.

Endorsement European Renal Association-European Dialysis and Transplant Association (ERA-EDTA) endorsed the scientific program of symposium.

\section{References}

1. Sakhaee K, Maalouf NM, Sinnott B (2012) Clinical review. Kidney stones 2012: pathogenesis, diagnosis, and management. J Clin Endocrinol Metab 97(6):1847-1860

2. Romero V, Akpinar H, Assimos DG (2010) Kidney stones: a global picture of prevalence, incidence, and associated risk factors. Rev Urol 12(2-3):e86-e96

3. Shuster J, Scheaffer RL (1984) Economic impact of kidney stones in white male adults. Urology 24(4):327-331

4. Cone EB, Hammill BG, Routh JC, Lipkin ME, Preminger GM, Schmader KE et al (2018) Disproportionate use of inpatient care by older adults with kidney stones. Urology 120:103-108

5. Scales CD Jr, Smith AC, Hanley JM, Saigal CS, Urologic Diseases in America P (2012) Prevalence of kidney stones in the United States. Eur Urol 62(1):160-165

6. Zeng G, Mai Z, Xia S, Wang Z, Zhang K, Wang L et al (2017) Prevalence of kidney stones in China: an ultrasonography based cross-sectional study. BJU Int 120(1):109-116

7. Ramello A, Vitale C, Marangella M (2000) Epidemiology of nephrolithiasis. J Nephrol 13(Suppl 3):S45-S50

8. Xu LHR, Adams-Huet B, Poindexter JR, Maalouf NM, Moe OW, Sakhaee K (2017) Temporal changes in kidney stone composition and in risk factors predisposing to stone formation. $\mathrm{J}$ Urol 197(6): 1465-1471

9. Shavit L, Ferraro PM, Johri N, Robertson W, Walsh SB, Moochhala S et al (2015) Effect of being overweight on urinary metabolic risk factors for kidney stone formation. Nephrol Dial Transpl 30(4):607-613

10. Daudon M (2005) [Epidemiology of nephrolithiasis in France]. Ann Urol (Paris) 39(6):209-231

11. Mandel N, Mandel I, Fryjoff K, Rejniak T, Mandel G (2003) Conversion of calcium oxalate to calcium phosphate with recurrent stone episodes. J Urol 169(6):2026-2029

12. Daudon M, Donsimoni R, Hennequin C, Fellahi S, Le Moel $\mathrm{G}$, Paris M et al (1995) Sex- and age-related composition of 10617 calculi analyzed by infrared spectroscopy. Urol Res 23(5):319-326

13. Rule AD, Bergstralh EJ, Melton LJ 3rd, Li X, Weaver AL, Lieske JC (2009) Kidney stones and the risk for chronic kidney disease. Clin J Am Soc Nephrol 4(4):804-811

14. Maeda S, Naganuma T, Takemoto Y, Shoji T, Okamura M, Nakatani T (2012) Chronic kidney disease in urolithiasis 
patients following successful extracorporeal shockwave lithotripsy. Mol Med Rep 5(1):3-6

15. Shang W, Li L, Ren Y, Ge Q, Ku M, Ge S et al (2017) History of kidney stones and risk of chronic kidney disease: a metaanalysis. PeerJ 5:e2907

16. Rule AD, Krambeck AE, Lieske JC (2011) Chronic kidney disease in kidney stone formers. Clin J Am Soc Nephrol 6(8):2069-2075

17. Goldfarb DS, Fischer ME, Keich Y, Goldberg J (2005) A twin study of genetic and dietary influences on nephrolithiasis: a report from the Vietnam Era Twin (VET) Registry. Kidney Int 67(3):1053-1061

18. Gambaro G, Vezzoli G, Casari G, Rampoldi L, D’Angelo A, Borghi L (2004) Genetics of hypercalciuria and calcium nephrolithiasis: from the rare monogenic to the common polygenic forms. Am J Kidney Dis 44(6):963-986

19. Edvardsson VO, Palsson R, Indridason OS, Thorvaldsson S, Stefansson K (2009) Familiality of kidney stone disease in Iceland. Scand J Urol Nephrol 43(5):420-424

20. Guerra A, Folesani G, Nouvenne A, Ticinesi A, Allegri F, Pinelli S et al (2016) Family history influences clinical course of idiopathic calcium nephrolithiasis: case-control study of a large cohort of Italian patients. J Nephrol 29(5):645-651

21. Toka HR, Genovese G, Mount DB, Pollak MR, Curhan GC (2013) Frequency of rare allelic variation in candidate genes among individuals with low and high urinary calcium excretion. PLoS One 8(8):e71885

22. Thorleifsson G, Holm H, Edvardsson V, Walters GB, Styrkarsdottir U, Gudbjartsson DF et al (2009) Sequence variants in the CLDN14 gene associate with kidney stones and bone mineral density. Nat Genet 41(8):926-930

23. Yasui T, Okada A, Urabe Y, Usami M, Mizuno K, Kubota Y et al (2013) A replication study for three nephrolithiasis loci at $5 q 35.3,7 \mathrm{p} 14.3$ and $13 \mathrm{q} 14.1$ in the Japanese population. J Hum Genet 58(9):588-593

24. Oliveira B, Kleta R, Bockenhauer D, Walsh SB (2016) Genetic, pathophysiological, and clinical aspects of nephrocalcinosis. Am J Physiol Renal Physiol 311(6):F1243-F1252

25. Shavit L, Jaeger P, Unwin RJ (2015) What is nephrocalcinosis? Kidney Int 88(1):35-43

26. Michalus I, Rusinska A (2018) Rare, genetically conditioned forms of rickets: Differential diagnosis and advances in diagnostics and treatment. Clin Genet 94(1):103-114

27. Sayer JA, Carr G, Simmons NL (2004) Nephrocalcinosis: molecular insights into calcium precipitation within the kidney. Clin Sci (Lond) 106(6):549-561

28. Taguchi K, Yasui T, Milliner DS, Hoppe B, Chi T (2017) Genetic risk factors for idiopathic urolithiasis: a systematic review of the literature and causal network analysis. Eur Urol Focus 3(1):72-81

29. Halbritter J, Baum M, Hynes AM, Rice SJ, Thwaites DT, Gucev ZS et al (2015) Fourteen monogenic genes account for $15 \%$ of nephrolithiasis/nephrocalcinosis. J Am Soc Nephrol 26(3):543-551

30. Braun DA, Lawson JA, Gee HY, Halbritter J, Shril S, Tan $\mathrm{W}$ et al (2016) Prevalence of monogenic causes in pediatric patients with nephrolithiasis or nephrocalcinosis. Clin J Am Soc Nephrol 11(4):664-672

31. Daga A, Majmundar AJ, Braun DA, Gee HY, Lawson JA, Shril $\mathrm{S}$ et al (2018) Whole exome sequencing frequently detects a monogenic cause in early onset nephrolithiasis and nephrocalcinosis. Kidney Int 93(1):204-213

32. Pelle A, Cuccurullo A, Mancini C, Sebastiano R, Stallone G, Negrisolo S et al (2017) Updated genetic testing of Italian patients referred with a clinical diagnosis of primary hyperoxaluria. J Nephrol 30(2):219-225
33. Diefenhardt P, Nosko A, Kluger MA, Richter JV, Wegscheid C, Kobayashi $Y$ et al (2018) IL-10 receptor signaling empowers regulatory $\mathrm{T}$ cells to control Th17 responses and protect from GN. J Am Soc Nephrol 29(7):1825-1837

34. Cloutier J, Villa L, Traxer O, Daudon M (2015) Kidney stone analysis: "Give me your stone, I will tell you who you are!". World J Urol 33(2):157-169

35. Siener R, Buchholz N, Daudon M, Hess B, Knoll T, Osther PJ et al (2016) Quality assessment of urinary stone analysis: results of a multicenter study of laboratories in Europe. PLoS One 11(6): 0156606

36. Daudon M, Dessombz A, Frochot V, Letavernier E, Haymann JP, Jungers P, Bazin D (2016) Comprehensive morpho-constitutional analysis of urinary stones improves etiological diagnosis and therapeutic strategy of nephrlithiasis. C R Chim 19:1470-1491

37. Reveillaud RJ, Daudon M, Protat MF, Ayrole G (1980) Analysis of urinary calculi in adults. Attempt of correlations between morphology and composition. Eur Urol 6(3):161-165

38. Daudon M, Estepa L, Lacour B, Jungers P (1998) Unusual morphology of calcium oxalate calculi in primary hyperoxaluria. $\mathrm{J}$ Nephrol 11(Suppl 1):51-55

39. Sakhaee K, Maalouf NM (2008) Metabolic syndrome and uric acid nephrolithiasis. Semin Nephrol 28(2):174-180

40. Maalouf NM, Cameron MA, Moe OW, Adams-Huet B, Sakhaee $\mathrm{K}$ (2007) Low urine $\mathrm{pH}$ : a novel feature of the metabolic syndrome. Clin J Am Soc Nephrol 2(5):883-888

41. Moe OW, Xu LHR (2018) Hyperuricosuric calcium urolithiasis. J Nephrol 31(2):189-196

42. Goldfarb DS, Hirsch J. Hypothesis (2015) Urbanization and exposure to urban heat islands contribute to increasing prevalence of kidney stones. Med Hypotheses 85(6):953-957

43. Ferraro PM, Curhan GC, D'Addessi A, Gambaro G (2017) Risk of recurrence of idiopathic calcium kidney stones: analysis of data from the literature. J Nephrol 30(2):227-233

44. Vervaet BA, Verhulst A, D’Haese PC, De Broe ME (2009) Nephrocalcinosis: new insights into mechanisms and consequences. Nephrol Dial Transpl 24(7):2030-2035

45. Vervaet BA, D'Haese PC, De Broe ME, Verhulst A (2009) Crystalluric and tubular epithelial parameters during the onset of intratubular nephrocalcinosis: illustration of the 'fixed particle' theory in vivo. Nephrol Dial Transpl 24(12):3659-3668

46. Vervaet BA, Verhulst A, De Broe ME, D'Haese PC (2010) The tubular epithelium in the initiation and course of intratubular nephrocalcinosis. Urol Res 38(4):249-256

47. Verhulst A, Asselman M, De Naeyer S, Vervaet BA, Mengel M, Gwinner W et al (2005) Preconditioning of the distal tubular epithelium of the human kidney precedes nephrocalcinosis. Kidney Int 68(4): 1643-1647

48. Letavernier E, Vandermeersch S, Traxer O, Tligui M, Baud L, Ronco P et al (2015) Demographics and characterization of 10,282 Randall plaque-related kidney stones: a new epidemic? Medicine (Baltimore) 94(10):e566

49. Verrier C, Bazin D, Huguet L, Stephan O, Gloter A, Verpont MC et al (2016) Topography, composition and structure of incipient randall plaque at the nanoscale level. J Urol 196(5):1566-1574

50. Letavernier E, Daudon M (2018) Vitamin D, Hypercalciuria and kidney stones. Nutrients 10(3):366

51. Letavernier E, Daudon M. Stones (2016) Tolvaptan might prevent kidney stone formation. Nat Rev Urol 13(3):130-131

52. Letavernier E, Kauffenstein G, Huguet L, Navasiolava N, Bouderlique E, Tang E et al (2018) ABCC6 deficiency promotes development of randall plaque. J Am Soc Nephrol 29:2337-2347

53. Kumakura S, Nakaya I, Sakuma T, Sato H, Soma J (2016) Crystalline cast nephropathy in a patient with IgD lambda myeloma. Clin Exp Nephrol 20(3):491-492 
54. Gupta V, El Ters M, Kashani K, Leung N, Nasr SH (2015) Crystalglobulin-induced nephropathy. J Am Soc Nephrol 26(3):525-529

55. Chatchen S, Pongsakul N, Srisomsap C, Chiangjong W, Hongeng S, Svasti J et al (2018) Unravelling pathophysiology of crystalline nephropathy in ceftriaxone-associated acute kidney injury: a cellular proteomic approach. Nephron 139(1):70-82

56. Carbone LG, Bendixen B, Appel GB (1988) Sulfadiazineassociated obstructive nephropathy occurring in a patient with the acquired immunodeficiency syndrome. Am J Kidney Dis 12(1):72-75

57. Sawyer MH, Webb DE, Balow JE, Straus SE (1988) Acyclovirinduced renal failure. Clinical course and histology. Am J Med 84(6):1067-1071

58. Nasr SH, Milliner DS, Wooldridge TD, Sethi S (2014) Triamterene crystalline nephropathy. Am J Kidney Dis 63(1):148-152

59. Santoriello D, Al-Nabulsi M, Reddy A, Salamera J, D'Agati VD, Markowitz GS (2017) Atazanavir-associated crystalline nephropathy. Am J Kidney Dis 70(4):576-580

60. Daudon M, Frochot V, Bazin D, Jungers P (2018) Drug-induced kidney stones and crystalline nephropathy: pathophysiology, prevention and treatment. Drugs 78(2):163-201

61. Cartery C, Faguer S, Karras A, Cointault O, Buscail L, Modesto A et al (2011) Oxalate nephropathy associated with chronic pancreatitis. Clin J Am Soc Nephrol 6(8):1895-1902

62. Chuang YW, Wen MC, Wu MJ, Shu KH, Cheng CH, Yu TM et al (2012) Follow-up and treatment of renal transplantation with nephropathic cystinosis in central Taiwan. Transpl Proc 44(1):80-82

63. Ceballos-Picot I, Perignon JL, Hamet M, Daudon M, Kamoun $\mathrm{P}$ (1992) 2,8-Dihydroxyadenine urolithiasis, an underdiagnosed disease. Lancet 339(8800):1050-1051

64. Bollee G, Cochat P, Daudon M (2015) Recurrence of crystalline nephropathy after kidney transplantation in APRT deficiency and primary hyperoxaluria. Can J Kidney Health Dis 2:31

65. Fogazzi GB (1996) Crystalluria: a neglected aspect of urinary sediment analysis. Nephrol Dial Transpl 11(2):379-387

66. Daudon M, Frochot V (2015) Crystalluria. Clin Chem Lab Med 53(Suppl 2):s1479-87

67. Scales CD Jr, Tasian GE, Schwaderer AL, Goldfarb DS, Star RA, Kirkali Z (2016) Urinary stone disease: advancing knowledge, patient care, and population health. Clin J Am Soc Nephrol 11(7):1305-1312

68. Tasian GE, Ross ME, Song L, Sas DJ, Keren R, Denburg MR et al (2016) Annual incidence of nephrolithiasis among children and adults in South Carolina from 1997 to 2012. Clin J Am Soc Nephrol 11(3):488-496

69. Jungers P, Joly D, Barbey F, Choukroun G, Daudon M (2004) ESKD caused by nephrolithiasis: prevalence, mechanisms, and prevention. Am J Kidney Dis 44(5):799-805

70. Alexander RT, Hemmelgarn BR, Wiebe N, Bello A, Morgan C, Samuel S et al (2012) Kidney stones and kidney function loss: a cohort study. BMJ 345:e5287

71. Denburg MR, Jemielita TO, Tasian GE, Haynes K, Mucksavage $\mathrm{P}$, Shults J et al (2016) Assessing the risk of incident hypertension and chronic kidney disease after exposure to shock wave lithotripsy and ureteroscopy. Kidney Int 89(1):185-192

72. El-Zoghby ZM, Lieske JC, Foley RN, Bergstralh EJ, Li X, Melton LJ 3rd et al (2012) Urolithiasis and the risk of ESKD. Clin J Am Soc Nephrol 7(9):1409-1415

73. Gambaro G, Croppi E, Bushinsky D, Jaeger P, Cupisti A, Ticinesi A et al (2017) The risk of chronic kidney disease associated with urolithiasis and its urological treatments: a review. J Urol 198(2):268-273
74. Spatola L, Angelini C, Badalamenti S, Maringhini S, Gambaro G (2017) Kidney stones diseases and glycaemic statuses: focus on the latest clinical evidences. Urolithiasis 45(5):457-460

75. Worcester EM, Parks JH, Evan AP, Coe FL (2006) Renal function in patients with nephrolithiasis. J Urol 176(2):600-603 (discussion 3)

76. Connors BA, Evan AP, Willis LR, Blomgren PM, Lingeman JE, Fineberg NS (2000) The effect of discharge voltage on renal injury and impairment caused by lithotripsy in the pig. J Am Soc Nephrol 11(2):310-318

77. Petrucci I, Clementi A, Sessa C, Torrisi I, Meola M (2018) Ultrasound and color Doppler applications in chronic kidney disease. J Nephrol 31(6):863-879

78. Zerwekh JE, Hwang TI, Poindexter J, Hill K, Wendell G, Pak CY (1988) Modulation by calcium of the inhibitor activity of naturally occurring urinary inhibitors. Kidney Int 33(5):1005-1008

79. Ettinger B, Citron JT, Livermore B, Dolman LI (1988) Chlorthalidone reduces calcium oxalate calculous recurrence but magnesium hydroxide does not. J Urol 139(4):679-684

80. Norman DA, Zerwekh JE, Pak CY (1981) An apparent 1,25-dihydroxyvitamin D-independent stimulation of intestinal calcium absorption in patients with Paget disease of bone during a shortterm diphosphonate therapy. Metabolism 30(3):290-292

81. Tebben PJ, Milliner DS, Horst RL, Harris PC, Singh RJ, Wu Y et al (2012) Hypercalcemia, hypercalciuria, and elevated calcitriol concentrations with autosomal dominant transmission due to CYP24A1 mutations: effects of ketoconazole therapy. J Clin Endocrinol Metab 97(3):E423-E427

82. Kaufman DW, Kelly JP, Curhan GC, Anderson TE, Dretler SP, Preminger GM et al (2008) Oxalobacter formigenes may reduce the risk of calcium oxalate kidney stones. J Am Soc Nephrol 19(6):1197-1203

83. Ricagno S, Jonsson S, Richards N, Lindqvist Y (2003) Formyl$\mathrm{CoA}$ transferase encloses the CoA binding site at the interface of an interlocked dimer. EMBO J 22(13):3210-3219

84. Siener R, Bangen U, Sidhu H, Honow R, von Unruh G, Hesse A (2013) The role of Oxalobacter formigenes colonization in calcium oxalate stone disease. Kidney Int 83(6):1144-1149

85. Maalouf NM, Moe OW, Adams-Huet B, Sakhaee K (2011) Hypercalciuria associated with high dietary protein intake is not due to acid load. J Clin Endocrinol Metab 96(12):3733-3740

86. Ticinesi A, Guerra A, Allegri F, Nouvenne A, Cervellin G, Maggio $\mathrm{M}$ et al (2018) Determinants of calcium and oxalate excretion in subjects with calcium nephrolithiasis: the role of metabolic syndrome traits. J Nephrol 31(3):395-403

87. Adami S, Marcocci C, Gatti D (2002) Epidemiology of primary hyperparathyroidism in Europe. J Bone Miner Res 17(Suppl 2):N18-N23

88. Bilezikian JP, Silverberg SJ (2004) Clinical practice. Asymptomatic primary hyperparathyroidism. N Engl J Med 350(17):1746-1751

89. Lal G, Clark OH (2003) Primary hyperparathyroidism: controversies in surgical management. Trends Endocrinol Metab 14(9):417-422

90. Bilezikian JP, Potts JT Jr, Fuleihan Gel H, Kleerekoper M, Neer $\mathrm{R}$, Peacock M et al (2002) Summary statement from a workshop on asymptomatic primary hyperparathyroidism: a perspective for the 21st century. J Clin Endocrinol Metab 87(12):5353-5361

91. Bilezikian JP, Potts JT Jr (2002) Asymptomatic primary hyperparathyroidism: new issues and new questions-bridging the past with the future. J Bone Miner Res 17(Suppl 2):N57-N67

92. Ruda JM, Hollenbeak CS, Stack BC Jr (2005) Jr. A systematic review of the diagnosis and treatment of primary hyperparathyroidism from 1995 to 2003. Otolaryngol Head Neck Surg 132(3):359-372 
93. Daudon M, Lacour B, Jungers P (2006) Influence of body size on urinary stone composition in men and women. Urol Res 34(3):193-199

94. Sakhaee K (2008) Nephrolithiasis as a systemic disorder. Curr Opin Nephrol Hypertens 17(3):304-309

95. Sakhaee K (2014) Epidemiology and clinical pathophysiology of uric acid kidney stones. J Nephrol 27(3):241-245

96. Maalouf NM, Cameron MA, Moe OW, Sakhaee K (2010) Metabolic basis for low urine $\mathrm{pH}$ in type 2 diabetes. Clin J Am Soc Nephrol 5(7):1277-1281

97. Daudon M, Traxer O, Conort P, Lacour B, Jungers P (2006) Type 2 diabetes increases the risk for uric acid stones. J Am Soc Nephrol 17(7):2026-2033

98. Fernandez A, Fuller A, Al-Bareeq R, Nott L, Razvi H (2013) A comparison of the metabolic profiles of diabetic and non-diabetic uric acid stone formers. Can Urol Assoc J 7(3-4):E190-E192

99. Nikiforova VJ, Giesbertz P, Wiemer J, Bethan B, Looser R, Liebenberg V et al (2014) Glyoxylate, a new marker metabolite of type 2 diabetes. J Diabetes Res 2014:685204

100. Burdin DV, Kolobov AA, Brocker C, Soshnev AA, Samusik N, Demyanov AV et al (2016) Diabetes-linked transcription factor HNF4alpha regulates metabolism of endogenous methylarginines and beta-aminoisobutyric acid by controlling expression of alanine-glyoxylate aminotransferase 2. Sci Rep 6:35503

101. Curhan GC, Willett WC, Speizer FE, Spiegelman D, Stampfer MJ (1997) Comparison of dietary calcium with supplemental calcium and other nutrients as factors affecting the risk for kidney stones in women. Ann Intern Med 126(7):497-504

102. Sakhaee K, Poindexter JR, Griffith CS, Pak CY (2004) Stone forming risk of calcium citrate supplementation in healthy postmenopausal women. J Urol 172(3):958-961

103. Karp HJ, Ketola ME, Lamberg-Allardt CJ (2009) Acute effects of calcium carbonate, calcium citrate and potassium citrate on markers of calcium and bone metabolism in young women. Br J Nutr 102(9):1341-1347

104. Green JH, Booth C, Bunning R (2003) Acute effect of highcalcium milk with or without additional magnesium, or calcium phosphate on parathyroid hormone and biochemical markers of bone resorption. Eur J Clin Nutr 57(1):61-68

105. Ketha H, Singh RJ, Grebe SK, Bergstralh EJ, Rule AD, Lieske JC et al (2015) Altered calcium and vitamin D homeostasis in firsttime calcium kidney stone-formers. PLoS One 10(9):e0137350
106. Hu H, Zhang J, Lu Y, Zhang Z, Qin B, Gao H et al. Association between circulating vitamin $D$ Level and urolithiasis: a systematic review and meta-analysis. Nutrients. 2017;9(3):301

107. Bambach CP, Robertson WG, Peacock M, Hill GL (1981) Effect of intestinal surgery on the risk of urinary stone formation. Gut 22(4):257-263

108. Kumar R, Lieske JC, Collazo-Clavell ML, Sarr MG, Olson ER, Vrtiska TJ et al (2011) Fat malabsorption and increased intestinal oxalate absorption are common after Roux-en-Y gastric bypass surgery. Surgery 149(5):654-661

109. Lieske JC, Mehta RA, Milliner DS, Rule AD, Bergstralh EJ, Sarr MG (2015) Kidney stones are common after bariatric surgery. Kidney Int 87(4):839-845

110. Canales BK, Hatch M (2014) Kidney stone incidence and metabolic urinary changes after modern bariatric surgery: review of clinical studies, experimental models, and prevention strategies. Surg Obes Relat Dis 10(4):734-742

111. Pareek G, Armenakas NA, Panagopoulos G, Bruno JJ, Fracchia JA (2005) Extracorporeal shock wave lithotripsy success based on body mass index and Hounsfield units. Urology 65(1):33-36

112. Castiglione V, Jouret F, Bruyere O, Dubois B, Thomas A, Waltregny D et al (2015) [Epidemiology of urolithiasis in Belgium on the basis of a morpho-constitutional classification]. Nephrol Ther 11(1):42-49

113. Sakhaee K (2017) Medical measures for secondary prevention of urolithiasis. Eur Urol Focus 3(1):10-12

114. Sakhaee K, Harvey JA, Padalino PK, Whitson P, Pak CY (1993) The potential role of salt abuse on the risk for kidney stone formation. J Urol 150(2 Pt 1):310-312

115. Sakhaee K, Williams RH, Oh MS, Padalino P, Adams-Huet B, Whitson $\mathrm{P}$ et al (1993) Alkali absorption and citrate excretion in calcium nephrolithiasis. J Bone Miner Res 8(7):789-794

116. Gambaro G, Croppi E, Coe F, Lingeman J, Moe O, Worcester E et al (2016) Metabolic diagnosis and medical prevention of calcium nephrolithiasis and its systemic manifestations: a consensus statement. J Nephrol 29(6):715-734

Publisher's Note Springer Nature remains neutral with regard to jurisdictional claims in published maps and institutional affiliations. 